\title{
O MUNDO DA ADMINISTRACÃO PÚBLICA DAS ÁGUAS DO ESTADO DO RIO DE JANEIRO SEGUNDO O OLHAR DE UM ANTROPÓLOGO
}

\author{
Carlos José Saldanha Machado \\ Fundação Oswaldo Cruz - Brasil
}

Resumo: O objetivo deste artigo é contribuir para a viabilização da gestão sustentável dos recursos hídricos do Estado do Rio de Janeiro. Trata-se de sistematizar algumas reflexões resultantes de cinco anos de participação e observações do processo de implementação da Política Estadual de Recursos Hídricos, durante o período de março de 2000 a junho de 2004, complementadas com levantamentos e análises do arcabouço institucional-legal, visitas e conversas informais com funcionários dos órgãos do poder público estadual e leitura de coleções de normas jurídicas. Concluise afirmando que o Estado que apregoa como suas as funções de gerência do bem público, de fazedor e mantenedor das leis e, principalmente, de equanimidade no desempenho dos seus papéis revela, na prática, sua inépcia para cumprir essas funções $e$, mesmo, sua predileção por exercê-las, dependendo da situação social e/ou relacional das pessoas ou grupos envolvidos.

Palavras-chave: administração pública das águas, análise institucional, gestão sustentável das águas, Rio de Janeiro.

Abstract. The objective of this article is to contribute for the viability of the sustainable management of the water resources of the Rio de Janeiro state. It systemizes some reflections resultant of 5 years of participation and observation of the Water Resources State Politics implementation process, during the period of March 2000 to June 2004, complemented with researching and analyses of the institutional-legal set of norms, visits and informal conversation with employees of the agencies of the state public power and readings of rules of law collections. In conclusion, it is affirmative that the State that proclaims as its, the functions of the public good management, of maker and keeper of the laws and, mainly, of equanimity at the performance of its role, discloses, in practice, its ineptitude to fulfill these functions and even, its predilection for exerting them, depending on the social and/or relational situation of the people or groups involved.

Keywords: institutional analysis, Rio de Janeiro, water public administration, water sustainable management. 


\section{Introduç̃o}

Até 1960, mais da metade da população brasileira vivia no campo. Ao longo das últimas quatro décadas, a situação se inverteu: hoje, apenas 19\% da população vivem no campo, enquanto 81\% vivem em centros urbanos (IBGE, 2003b). Como conseqüência desse fenômeno de explosão urbana, a qualidade das fontes disponíveis de água vem se tornando cada vez mais comprometida ou correndo risco de deterioração como resultado da concentração demográfica junto a rios, córregos, lagos e lagoas que são usados para a diluição do esgoto doméstico e de efluentes industriais, bem como da ausência rotineira do poder público no exercício de fiscalização e controle dos usos desses recursos pelos atores da dinâmica territorial. Geograficamente, essa realidade se expressa de forma dramática nas regiões metropolitanas onde, segundo a Pesquisa de Informações Básicas Municipais 2001 do IBGE (2003a), 78,6\% dos municípios têm favelas em seus territórios.

Nesse contexto de degradação socioambiental, é digno de nota, no Estado do Rio de Janeiro, o fato de que a bacia hidrográfica do rio Guandu (uma bacia de transposição das águas do rio Paraíba do Sul), responsável pelo abastecimento de 8,5 milhões de pessoas da região metropolitana do Rio de Janeiro, vem correndo o risco de atingir um nível tão alto de poluição que sua água não possa ser mais economicamente tratada para torná-la potável nos próximos anos. ${ }^{1}$ Atualmente essa situação vem sendo contornada através do crescente uso de produtos químicos (cloro gasoso, sulfato de alumínio, cal, cloreto férrico, flúor e polieletrólitos) pela Companhia Estadual de Água e Esgoto (Cedae) (Do

\footnotetext{
1 Também merece destaque a bacia hidrográfica da Barra da Tijuca e de Jacarepaguá, única bacia localizada integralmente no Município do Rio de Janeiro, na zona costeira do território fluminense, com cerca de $300 \mathrm{~km}^{2}$ de superfície, formada por 41 rios e cinco lagoas. Segundo o Censo 2000 do IBGE (2003b), a população total da bacia é de 943 mil pessoas, distribuídas entre 18 bairros, ou seja, um sexto da população do município. A taxa de crescimento populacional na bacia entre 1991 e 2000 foi de 6,7\% ao ano, ao passo que no Município do Rio de Janeiro foi de $0,7 \%$ ao ano, ou seja, dez vezes mais. A população residente em favelas é de 184 mil pessoas, representando 19,5\% da população total. Além disso, destacam-se na bacia regiões de grande carência social, mesmo que não classificadas com áreas de favelas, tais como a Cidade de Deus, com 51 mil habitantes.
}

Horizontes Antropológicos, Porto Alegre, ano 12, n. 25, p. 171-190, jan./jun. 2006 
Paraíba..., 2004) para que o tratamento diário da água na estação de tratamento atenda aos padrões de qualidade fixados pelo Ministério da Saúde.

Diante dessa dimensão da questão ambiental brasileira, ${ }^{2}$ e da saúde pública, o governo federal toma como base o modelo francês de gestão das águas ${ }^{3}$ para formular, em meados dos anos 1980, um modelo cujo objetivo era minorar os problemas existentes num país onde ainda convive a cultura da abundância e da finitude dos recursos naturais. Após ter sido aprovado, no final de 1996, pelo Congresso Nacional, o Projeto de Lei das Águas, o presidente da República sanciona a lei no 9.433, em 8 de janeiro de 1997, instituindo a Política Nacional de Recursos, cujos princípios básicos são o gerenciamento por bacia hidrográfica, a água como bem econômico, a descentralização, a integração e a participação dos usuários no processo de gestão de recursos hídricos.

A partir de então os estados-membros da federação passaram a discutir, fundamentar e/ou atualizar, em ritmos diferenciados, seus respectivos arcabouços jurídico-legais sobre recursos hídricos e a redefinir suas políticas para o setor (Machado, 2004b). No bojo desse processo, desde agosto de 1999, o Estado do Rio de Janeiro vem demonstrando que está empenhado em implementar seu sistema de gerenciamento de recursos hídricos promulgando, em 9 de agosto, a lei no 3.239. A lei sobre gestão das águas como recursos hídricos, isto é, a água na condição de bem econômico, estabelece a doutrina, os objetivos, as diretrizes, o arranjo institucional, os mecanismos e os instrumentos da Política e do Sistema Estadual de Gerenciamento de Recursos

\footnotetext{
2 Convém enfatizar que a questão ambiental, da qual faz parte a gestão dos recursos hídricos, emergiu efetivamente no interior do Estado quando da promulgação da lei Federal nำ 6.938, em 31 de agosto de 1981, que institui a Política Nacional do Meio Ambiente. A partir de então, o Estado foi obrigado a se posicionar como instância reguladora das relações e interações entre as diversas dinâmicas sociais concretas - portadoras de lógicas, representações, valores e visões de mundo diferentes e, muitas vezes, conflitantes - e a materialidade. Tal fato implicou o desenvolvimento de inúmeras estratégias, tanto por parte do Estado - por meio da formulação de políticas, normas e regulações ou, ao contrário, por meio da desregulamentação de atividades - quanto da sociedade - por meio da organização e formulação de demandas, que incluíam um espaço de participação no processo decisório das políticas relacionadas ao meio ambiente e o estabelecimento de direitos, entre outras. Para uma descrição e análise desse processo, ver Machado (2000).

3 Para uma análise dos princípios jurídicos da experiência francesa de gestão de água potável e de saneamento de águas servidas, ver Machado (2004a).
}

Horizontes Antropológicos, Porto Alegre, ano 12, n. 25, p. 171-190, jan./jun. 2006 
Hídricos. Contudo, como veremos a seguir, o Estado do Rio de Janeiro está longe de uma administração pública coerente com o gerenciamento integrado dos recursos hídricos preceituado, há 16 anos, na Constituição do Estado do Rio de Janeiro (capítulo VII, art. 261, parágrafo 1ํㅗ , inciso VII).

O objetivo deste artigo é contribuir para o processo de viabilização da gestão sustentável dos recursos hídricos no Estado do Rio de Janeiro que, se implementada pelo poder público com base nos fundamentos da lei, concorrerá, sobremaneira, para a melhoria da qualidade de vida de segmentos expressivos da população fluminense, sobretudo daqueles que vivem em favelas, ${ }^{4}$ fazem uso in natura das águas superficiais e subterrâneas e arcam com as conseqüências biológicas resultantes dos baixos padrões da qualidade da água consumida. ${ }^{5}$ Trata-se de sistematizar algumas reflexões resultantes de cinco anos de participação e observação do processo de implementação da Política de Recursos Hídricos do Estado do Rio de Janeiro, durante o período de março de 2000 a junho de 2004, quando, então, assessorei a ex-secretária de Estado de Saneamento e Recursos Hídricos do Rio de Janeiro, presidi a Câmara Técnica de Sistema de Gestão do Conselho Estadual de Recursos Hídricos do Estado do Rio de Janeiro (CERHI-RJ) e representei o Fórum de Reitores das Universidades do Rio de Janeiro no CERHI-RJ. Tais reflexões foram complementadas com levantamentos e análises do arcabouço institucionallegal que disciplina, organiza e norteia as ações relacionadas aos recursos hídricos do Estado do Rio de Janeiro, visitas e conversas informais com funcionários dos órgãos do poder público estadual (secretarias, autarquias e fundações), consulta ao Diário Oficial do Estado e leitura de coleções de normas jurídicas da Assembléia Legislativa, bem como da literatura especializada sobre o tema.

4 Com base na leitura da Pesquisa de Informações Básicas Municipais 2001 do IBGE (2003a), podese conceituar "favela” como sendo um conjunto de habitações em área pública ou privada, geralmente invadida, ocupada de forma desordenada e com infra-estrutura precária, onde as pessoas vivem apinhadas e os lotes não obedecem a um desenho regular, os acessos são tortuosos e não permitem a passagem de carros.

5 Para uma análise das relações entre degradação ambiental e distribuição desigual de seus efeitos entre os diferentes grupos sociais segundo classes de renda no Estado do Rio de Janeiro, ver Acselrad (2004). 


\section{Reorganizacão do ordenamento jurídico dos recursos hídricos e das condições materiais dos órgãos ambientais}

Quando se analisa globalmente a legislação ambiental do Estado do Rio de Janeiro (Machado; Klein, 2003), não resta dúvida de que ela tem como um de seus objetivos primordiais garantir a manutenção de um ambiente equilibrado e saudável para a população. Trata-se de um objetivo cuja importância para a perenidade da vida das pessoas e de todos os seres vivos se torna inquestionável, sobretudo se focarmos nossa atenção num tema como o da qualidade da água. Nesse tema, a interface entre o direito ambiental e o sanitário se torna ainda mais evidente em face da relação direta entre água, doença, contaminação, infecção e intoxicação.

Contudo, quando se observa localmente, e mais de perto, a organização do ordenamento jurídico dos recursos hídricos do Estado do Rio de Janeiro, fica evidente que para o poder público poder zelar pela saúde ambiental dos corpos d'água, de forma eficiente e eficaz, é preciso corrigir a desordem que se instaurou no ordenamento jurídico em face da fragmentação de seu sistema legal para que o Sistema Estadual de Gerenciamento de Recursos Hídricos funcione de acordo com os fundamentos do modelo brasileiro de gestão de recursos hídricos incorporados integralmente pela lei estadual no 3.239/99. Para tal, devese desencadear um processo de consolidação das normas com objetos idênticos, análogos, ou conexos, a fim de eliminar eventuais divergências, colisões ou repetições, e, assim, conferir unidade, simplicidade e coerência ao corpo legislativo estadual em matéria de recursos hídricos e meio ambiente. Simultaneamente, é indispensável também que os órgãos ambientais do estado - Fundação Superintendência Estadual de Rios e Lagoas (Serla), responsável direta pela gestão e controle do uso dos recursos hídricos no Estado; Fundação Estadual de Engenharia do Meio Ambiente (Feema), responsável direta pela gestão e controle da qualidade da água; Instituto Estadual de Florestas (IEF), responsável direto pela gestão da floresta de Mata Atlântica - sejam retirados da condição de sucateamento em que se encontram desde o final dos anos 1980. Dois exemplos distintos de uma mesma realidade, registrados há dois anos pelo jornal O Globo (Órgãos ambientais..., 2003), mas que continuam na ordem do dia, dão a dimensão exata do problema estrutural da administração pública das águas do Rio de Janeiro. Enquanto a Serla tinha até o final de 2002 apenas 12 máquinas, entre dragas e escavadeiras, em más condições, para cobrir a área 
total de 43.909,7 $\mathrm{km}^{2}$ do territorial fluminense, ${ }^{6}$ um engenheiro da Feema, com 22 anos de trabalho, ganhava um salário-base de $\mathrm{R} \$ 400,00$ (quatrocentos reais)!

\section{A determinação do valor da cobrança pelo uso da água}

Uma vez que o modelo de gestão das águas está baseado em um contínuo processo de negociações e de resolução de conflitos, envolvendo diferentes segmentos da sociedade, numa administração cooperada e participativa, os instrumentos dessa gestão têm como objetivo facilitar a busca dos necessários consensos, colocando à disposição de todos as informações e as simulações técnicas, institucionais, econômicas e financeiras que dêem sustentação às propostas para o desenvolvimento e controle da utilização dos recursos naturais, nesse caso, a água doce.

Nesse sentido, se a outorga de direito de uso ${ }^{7}$ visa reduzir conflitos e permitir o controle da qualidade e da quantidade da água, assegurando o direito de uso da água ao outorgado, a cobrança, por sua vez, procura induzir o usuário à adoção de uma postura de racionalidade. Portanto, elas se complementam. Os objetivos da implementação da cobrança pelo uso da água podem ser assim

6 O território fluminense apresenta características muito peculiares, dado que sua configuração é de uma estreita faixa de terra que se desenvolve ao longo do oceano Atlântico, apresentando a terceira maior faixa de litoral do país, com mais de $630 \mathrm{~km}$ de extensão e todas as suas bacias hidrográficas vertendo para o oceano. O regime dos cursos d’água do estado sofre grande influência do relevo e da proximidade do oceano Atlântico. A serra do Mar, que representa importante papel como divisor natural de águas, atravessando o território, longitudinalmente, desde o município de Paraty, ao Sul, até o município de Campos dos Goytacazes, ao norte, separa a drenagem natural em duas principais vertentes: a do Rio Paraíba do Sul e a do oceano Atlântico, esta última chamada de Vertente Atlântica pelos geógrafos. A maior bacia hidrográfica do estado é a do rio Paraíba do Sul, que nasce no Estado de São Paulo, recebe afluentes de Minas Gerais e do Rio de Janeiro, onde encerra seu curso, desaguando no oceano Atlântico. A área de drenagem total da bacia é de cerca de 56.600 km², sendo aproximadamente $22.600 \mathrm{~km}^{2}$ no Estado do Rio de Janeiro.

7 Outorga quer dizer consentimento, assentimento, assenso, anuência, aprovação, beneplácito. Indica a intenção do ato administrativo mediante o qual o poder público, investido do poder outorgante, faculta ao administrado, ora outorgado, o direito ao uso de certa quantidade de água bruta de manancial (água tal como é encontrada nos mananciais, superficiais ou subterrâneos, independentemente de seu nível de qualidade), medida na unidade de tempo, estabelecendo, quando for o caso, o regime de utilização (“turnos”) e outras restrições que se façam necessárias, por tempo determinado. A outorga constitui uma manifestação de vontade do poder executivo, e objetiva assegurar o controle quantitativo e qualitativo dos usos da água, ao mesmo tempo que garante o direito do usuário outorgado.

Horizontes Antropológicos, Porto Alegre, ano 12, n. 25, p. 171-190, jan./jun. 2006 
resumidos: a) gerenciar a demanda; b) redistribuir os custos sociais, uma vez que os preços a serem cobrados serão diferenciados de acordo com a capacidade econômica do usuário; c) melhorar a qualidade dos esgotos, urbanos e industriais; d) formar fundos para as obras e outras formas de intervenções no espaço da bacia hidrográfica; e, finalmente, e) fazer incorporar ao planejamento global as dimensões social e ambiental de que se reveste o problema da água de mananciais. Para que tais objetivos sejam alcançados de forma perene, o valor da cobrança deveria ser determinado pela interação entre a demanda e a oferta de água de determinado tipo, em determinada localidade e em determinado período de tempo (Machado, 2003).

Uma forma democrática de determinação do valor da cobrança pelo uso da água de uma bacia hidrográfica é a pesquisa sobre a disposição a pagar do consumidor. Ela pode ser obtida por métodos diretos e indiretos. ${ }^{8} \mathrm{O}$ método direto, também conhecido como método de avaliação contingente, consiste na opção de perguntar explicitamente às pessoas, por meio de pesquisas amostrais, o quanto elas estariam dispostas a pagar pelo bem. Os métodos indiretos usam os preços relacionados ao comportamento dos consumidores em mercados recorrentes. Dentre os métodos indiretos, destacam-se dois: o método dos índices hedônicos e o método de custos de viagem. O primeiro procura relacionar os diferenciais de preços de um bem às características qualitativas do mesmo, sendo uma destas características aquela que se pretende valorar. O segundo, por sua vez, atribui um preço ao bem de acordo com o custo que é assumido pelas pessoas para que o bem em questão seja usufruído. Em ambos os casos, são utilizados procedimentos estatísticos tanto para o estabelecimento da relação preço-qualidade ou preço-custo quanto para a obtenção do preço médio. A idéia básica da pesquisa é obter o montante que as pessoas estariam dispostas a pagar por um bem ou serviço para o qual não existe um mercado. É importante salientar que no contexto da gestão de bacias hidrográficas o bem não seria a água, mas a garantia do abastecimento, tanto em termos quantitativos quanto qualitativos; isso equivale a dizer que o objetivo é estimar quanto as pessoas estariam dispostas a pagar para que o objetivo de otimização de disponibilidade de recursos hídricos, em termos de quantidade e qualidade, seja alcançado, além da preservação ambiental.

8 Para uma sistematização e apresentação geral desses métodos, ver Machado (2004a). 
Na pesquisa de disposição a pagar, dentro de um estudo para a implementação da gestão de bacias hidrográficas e da cobrança pelo uso da água, deveria ser considerado que os recursos obtidos através dessa cobrança devem financiar parte dos investimentos, e que esses recursos necessariamente serão retirados das famílias que terão como contrapartida os benefícios diretos ou indiretos dos investimentos realizados. De um modo geral pode-se apontar como principais benefícios para as famílias a preservação ambiental da bacia, a melhoria da qualidade da água e a garantia da disponibilidade dos recursos no futuro. Desse modo, a questão que se coloca é saber qual o valor atribuído pelas famílias a esses benefícios, e não o valor da água em si. Colocado dessa forma, a disposição a pagar dependerá principalmente de como cada indivíduo avalia esses benefícios, o que por sua vez pode depender da experiência pessoal de cada um com relação a esses.

As pesquisas de disposição a pagar têm aplicação como alternativa para a obtenção do preço médio que poderia ser pago pelos consumidores finais, sendo inaplicável para se determinar o preço médio que se pretende seja pago pelos usuários que fornecem serviços relacionados aos recursos hídricos. Nesse último caso, qualquer que seja o preço cobrado, esse será repassado aos consumidores finais. Sob esse ponto de vista, a pesquisa de disposição a pagar se configuraria mais como um referencial a indicar qual o repasse aceito pelas pessoas. Dessa forma, torna-se irrelevante se as famílias pagarão direta ou indiretamente pelo uso da água, ou seja, se o preço estabelecido para o uso da água será cobrado diretamente do consumidor final ou da empresa de abastecimento. Desde que o indivíduo seja informado de que o adicional pago será utilizado para financiar parte dos investimentos que garantirão que se alcance determinado objetivo, ele deve ser indiferente entre pagar direta ou indiretamente.

Portanto, devido à sua natureza dinâmica, a implementação da cobrança torna-se uma tarefa a ser executa cautelosamente. Para a implementação eficiente e eficaz de um sistema de cobrança é preciso a elaboração de uma estratégia e de um plano que leve em consideração duas premissas básicas. Primeiro, a eficiência do sistema depende da participação dos agentes sociais envolvidos na gestão, exigindo uma articulação política-institucional voltada para a busca do consenso, articulação esta que deve ser empreendida junto ao poder público e ao setor privado da sociedade. Segundo, para que a integração dos diversos setores envolvidos no gerenciamento dos recursos hídricos seja efetiva, é indispensável que sejam considerados os aspectos institucionais e administrativos que possuem interfaces com o processo de efetivação do modelo de 
gestão. Portanto, um plano de implantação da cobrança deve considerar diferentes etapas que contemplem os diferentes objetivos e metas de curto, médio e longo prazo (Machado, 2003).

\section{A lei da cobrança pelo uso da água e o resgate de duas velhas tradicões republicanas}

Infelizmente, para tornar o processo de construção política da gestão sustentável das águas mais complicado e complexo no Estado do Rio de Janeiro, a recente edição da "Lei estadual no 4.247 sobre a cobrança pela utilização dos recursos hídricos de domínio do Estado do Rio de Janeiro, em 17 de dezembro de 2003”, trouxe modificações significativas para o sistema instituído pela lei estadual no 3.239/99. Segundo a nova lei, a cobrança deverá ser feita através de preço público, e os recursos provenientes de cada bacia hidrográfica não serão aplicados exclusivamente na bacia em que foram originados. A metodologia da cobrança foi estipulada, unilateralmente, pelo governo do estado, copiando literalmente a equação que define os valores que incidirá sobre os usuários de todos os setores da economia, equação construída pelos engenheiros do Laboratório de Hidrologia da COPPE/UFRJ para o Comitê Federal da Bacia do Rio Paraíba do Sul - Ceivap (deliberação no 08, de 06/12/2001 e no 15, de 04/11/ 2002), sem consultar o Conselho Estadual de Recursos Hídricos e os Comitês Estaduais de Bacias Hidrográficas existentes naquela ocasião. ${ }^{9}$ A Serla, órgão atualmente subordinado ao vice-governador, passou a centralizar as ações referentes à cobrança e à distribuição dos valores arrecadados. Ou seja, a nova lei estadual rompe com o que determina a lei federal no 9.433/97. Na prática, não haverá mais a necessidade de planos e de comitês de bacias hidrográficas, tornando impossível a gestão democrática e participativa de um bem de uso comum do povo, colidindo, portanto, com os princípios estabelecidos nos "artigos $1^{\circ}$, parágrafo VI; 6; 12 , inciso 2oㅜ 38 , parágrafo III e 39 da lei federal $n^{\circ}$ 9.433” que instituiu o modelo de gestão dos recursos hídricos brasileiro.

Ora, um dos resultados do processo de democratização do Estado brasileiro que se deu na década de 1980, foi justamente a ampliação da esfera

9 Até o final de 2003 haviam sido criados dois comitês de bacias hidrográficas. Hoje, há cinco comitês no Rio de Janeiro. 
pública no país, resultando na criação de órgãos colegiados tripartite (poder público, usuários e comunidade/sociedade civil). Na arena da gestão dos recursos naturais, os comitês de bacias hidrográficas foram criados com atribuições normativas, deliberativas e consultivas, reconhecidos e qualificados por ato do poder executivo, mediante proposta do Conselho Estadual de Recursos Hídricos, em função do atendimento dos critérios gerais estabelecidos pelo conselho, das necessidades da bacia hidrográfica e da capacidade de articulação entre seus membros (lei federal no 9433/97; lei estadual no 3239/99; resolução CERHI no 05/02). Cabe ao comitê de bacia a coordenação das atividades dos agentes públicos e privados, relacionados aos recursos hídricos e ambientais, devendo, para isso, compatibilizar metas e diretrizes do Plano Estadual de Recursos Hídricos com as peculiaridades da sua área de atuação.

Mas, indo na contramão da história contemporânea brasileira, o poder executivo estadual, além de não se sujeitar às normas federais relativas ao gerenciamento de recursos hídricos, ${ }^{10}$ resgata, a um só tempo, ao sancionar a lei no 4.247/03, duas velhas tradições republicanas: o autoritarismo e a centralização na administração pública (Chauí, 2001; Faoro, 1957). Ou seja, 15 anos depois de ser institucionalizado o modelo de gestão baseado na descentralização político-administrativa e na participação da população na formulação e no controle das ações de atenção à população em todos os níveis de governo, o poder executivo desconsidera as diretrizes constitucionais de democratização do Estado brasileiro. É como se o governo do território fluminense não soubesse que o Brasil tem diversos tipos de lei, mas que a Constituição se sobrepõe a todas, sendo chamada por isso, com freqüência, de Carta Magna. No sistema legislativo nenhuma lei pode contrariar a Constituição Federal, posto que ela é superior a qualquer legislação infraconstitucional e seus princípios orientam e norteiam o legislador que resolve inovar o sistema, o executor que precisa de parâmetros para exercer o seu ofício e o julgador que não pode se distanciar do núcleo central do sistema estatal.

Mas como interpretar as reais intenções do poder executivo em aprovar na Assembléia Legislativa do Estado do Rio de Janeiro (Alerj), durante o último mês do ano de 2003, em menos de duas semanas, um projeto de lei (n⿳․ㅜ‥085)

${ }^{10}$ Ao estabelecer um sistema de gestão dos recursos hídricos nacionais, a Constituição Federal de 1988 determina, em seu artigo 22, inciso IV, que compete privativamente à União legislar sobre águas.

Horizontes Antropológicos, Porto Alegre, ano 12, n. 25, p. 171-190, jan./jun. 2006 
de sua autoria em lei da cobrança pela utilização dos recursos hídricos de domínio do estado? Uma avaliação recente do Tribunal de Contas do Estado (2003) ajuda a dar uma interpretação consistente dos resultados a serem alcançados pelo governo do estado com a promulgação da lei estadual no 4.247. Ou seja, tendo em vista o fato do governo estadual não ter investido, durante o exercício fiscal de 2002, segundo avaliação das contas de gestão do governo pelo TCE$\mathrm{RJ}$, os percentuais mínimos estabelecidos constitucionalmente nas áreas de meio ambiente (R\$ 245 milhões), saúde (R\$ 75 milhões) e educação (R\$ 7 milhões), somos obrigados a admitir que o mesmo venha a ocorrer com o setor de recursos hídricos, sobretudo quando o grupo político que controla o aparelho de Estado ${ }^{11}$ precisa realizar obras e programas assistencialistas para se reeleger, e seu partido político, ou coligação, ter fluxo de caixa para alimentar a campanha de seus candidatos, sobretudo de seu candidato à presidência da República.

\section{As idéias de descentralização e de participação diante da cultura tecnocrática}

Como foi referido anteriormente, as idéias de descentralização e de participação adquiriram recentemente um novo sentido político, transformando-se em importantes palavras de ordem para os governos que têm sustentado a necessidade de modernização do Estado brasileiro. Fazer face às rápidas e amplas mudanças mundiais implica, não raro, criar arcabouços jurídico-institucionais para responder aos imperativos do sistema global. Dentre os princípios enumerados pela Constituição de 1988, o da descentralização político-admininstrativa é a contrapartida da emergência de um novo pacto federativo estabelecido no Brasil, a partir do momento em que aos municípios e, por conseqüência direta, às sociedades locais, é reconhecido e garantido o direito de formular e controlar políticas. Dessa forma, a descentralização ganha maior amplitude nos dias atuais, provocando um redirecionamento nas tradicionais relações entre Estado e sociedade, não dizendo respeito apenas às repartições de poder e de atribuições entre os diversos entes da federação, mas à assunção cada vez maior de responsabilidades e iniciativas à sociedade civil, através de suas diversas formas de organização.

\footnotetext{
${ }^{11}$ Entendo por aparelho de Estado a administração pública em sentido amplo, ou seja, a estrutura organizacional do Estado, em seus três poderes (executivo, legislativo e judiciário) e três níveis (União, estados-membros e municípios). O aparelho do Estado é constituído pelo governo, isto é, pela cúpula dirigente nos três poderes, por um corpo de funcionários, e pela força militar.
}

Horizontes Antropológicos, Porto Alegre, ano 12, n. 25, p. 171-190, jan./jun. 2006 
Nessa perspectiva, é relevante destacar que o princípio da gestão integrada, descentralizada e participativa no Rio de Janeiro é fundamental para a compreensão da lei enquanto instrumento de mudança de paradigma de política pública. ${ }^{12}$ A introdução desse tipo de gestão do bem público da água é inovadora, pois o poder público não mais terá a maioria de votos nos comitês de bacias hidrográficas porque se trata de uma gestão tripartite. Mas o princípio em questão deve ser motivo de conflitos entre sociedade civil e poder público, ${ }^{13}$ uma vez que há uma cultura administrativa de forte tradição tecnocrática, além de centralizadora, ainda bastante arraigada na administração pública brasileira. No caso dos recursos hídricos, essa cultura sobrevive através de toda uma geração de especialistas das mais variadas formações, sobretudo das engenharias, como foi acentuado anteriormente, que ocupam cargos decisórios em órgãos do poder público, detentores de conhecimentos sobre as bacias hidrográficas e agindo com base em extensas redes de relações socioprofissionais. Trata-se de funcionários públicos que compartilham a crença segundo a qual os técnicos são os que sabem o que é melhor para os cidadãos em matéria de recursos hídricos porque “a técnica é neutra”. Esses funcionários não entendem que as ciências e as tecnologias não devem tutelar a democracia direta na gestão sustentável das águas, pois nenhum desenvolvimento sustentável poderá existir sem a participação ampliada das populações envolvidas. A gestão integrada, descentralizada e participativa de uma bacia hidrográfica é um assunto sério demais para ficar nas mãos tão-somente dos técnicos do poder público porque uma atividade técnica gera, intrinsecamente, um processo de caráter político, já que sempre se deve escolher. Toda atividade é potencialmente política na medida em que a política tem por objetivo manter, legitimar, influenciar ou transformar as configurações, as ideologias e os valores por meio dos quais os indivíduos, os grupos e as sociedades organizam os recursos materiais e sociais. Ou seja, toda e qualquer decisão tomada com base em critérios técnicos serve a algum propósito político (Galimberti, 2004), tenhamos ou não consciência disso, posto que todo e qualquer técnico, enquanto pessoa humana, traz consigo os

\footnotetext{
${ }^{12}$ Para uma análise antropológica do modo de apropriação desses princípios pelos atores da dinâmica territorial do Estado de Minas Gerais no processo de formação dos comitês de bacias hidrográficas, ver Cardoso (2003).

${ }^{13}$ Para uma análise, no âmbito dos conflitos judiciais, da emergência e da disputa pela definição do meio ambiente como problema social no Rio de Janeiro, ver Fuks (2001).
}

Horizontes Antropológicos, Porto Alegre, ano 12, n. 25, p. 171-190, jan./jun. 2006 
valores políticos, éticos, morais e hábitos profissionais da sociedade e da cultura da qual faz parte, valores esses que norteiam suas ações profissionais e individuais. Uma pessoa se habitua a tal ponto com certas identidades que, mesmo quando sua situação socioprofissional muda, devido à adoção de uma nova política pública, ela encontra dificuldade para acompanhar as novas configurações da relação Estado-sociedade.

\section{Gestão territorial participativa e descentralizada com negociacãa sociotécnica}

Contudo, a lógica da gestão territorial participativa e descentralizada contida no modelo de gestão que norteia a relação Estado-sociedade e a administração pública das águas não pode esconder o fato de que o termo "participação” se acomoda a diferentes interpretações, já que se pode participar ou tomar parte em alguma coisa de formas diferentes, que podem variar da condição de simples espectador, mais ou menos marginal, à de protagonista de destaque. Assim, a pretendida e esperada participação da sociedade, dos usuários e das comunidades em geral é contemplada formalmente pela lei e garantida por meio de sua representação nos comitês e demais organismos de bacia hidrográfica, assim como nos conselhos estaduais e nacionais. Mas a participação efetiva e material da sociedade deve ser garantida também através de outros mecanismos, que valorizem as histórias particulares de cada localidade e as diversas contribuições das populações envolvidas, incorporando-as aos planos diretores e ao enquadramento dos cursos de água. ${ }^{14}$ Não se trata apenas de apresentar à população um plano diretor de bacia, elaborado no espaço de trabalho fechado do corpo técnico-científico do poder público, objetivando validá-lo, mas de garantir a efetiva participação da população local na consolidação e materialização de um pacto através da prática política do que chamamos de "gestão integrada com negociação sociotécnica". A base empírica do conhecimento local da população sobre os corpos d'água de uma bacia hidrográfica deve ser valorizada, pois possui um valor socioambiental inigualável.

\footnotetext{
${ }^{14}$ Enquadramento significa fazer um programa para assegurar às águas de um corpo d’água uma qualidade compatível com os usos mais exigentes a que forem destinadas. Ou seja, enquadramento, além de ser um cronograma de despoluição de rios, lagos e aqüíferos, é um valioso instrumento de política da gestão dos recursos hídricos, posto que oficializa metas para assegurar a disponibilidade de água no nível de qualidade requerido pela sociedade que vive na e da bacia hidrográfica.
}

Horizontes Antropológicos, Porto Alegre, ano 12, n. 25, p. 171-190, jan./jun. 2006 
Esquecê-lo pode, muitas vezes, redundar em políticas de intervenção de resultados desastrosos. É a população, que vive as águas de uma bacia hidrográfica, que se relaciona com os corpos d'água de diversas maneiras, fazendo seu uso para fins econômicos - como uso doméstico, produção agropecuária, pesca, entre outros, e também para fins recreativos e de transporte -, que arca com as conseqüências negativas de um plano diretor elaborado unilateralmente. Além disso, os cursos d'água fazem parte da história de vida das pessoas, da família e da comunidade que integram essa população, ganhando sentidos simbólicos que ocupam uma parte importante de seu patrimônio cultural.

Ou seja, a defesa da participação não envolve apenas princípio democrático de sentido humanista, filosófico ou, pior ainda, demagógico e retórico, mas é também parte importante na construção de uma nova forma de encarar a gestão de recursos públicos caros e escassos. Envolve a pressuposição de que uma pessoa envolvida na tomada de uma decisão sentir-se-á comprometida e procurará vê-la cumprida, será agente da implantação, e não paciente. De fato, a aceitação é maior quando existe participação em todo o processo de gestão de um projeto ou de uma política e quando o indivíduo faz sua própria escolha. Na gestão de bacias hidrográficas, a população envolvida é gestora e deve poder reconhecer como propriamente suas as decisões tomadas que resultam num plano diretor ou no enquadramento de um rio, ou pelo menos deve estar convicta de que elas são o resultado de um consenso possível, resultando das negociações com o corpo técnico do poder público, e demais atores da bacia hidrográfica, em que suas aspirações foram consideradas.

\section{Controle da qualidade das águas, desarticulação entre os órgãos públicos envolvidos e educação ambiental}

Em relação a uma importante dimensão da administração pública dos recursos hídricos, a da qualidade das águas do Estado, é preciso a produção de dados primários a fim de que a saúde, entendida como um direito de cidadania, seja alcançada de forma universal e eqüitativa no território fluminense. Para tanto, torna-se imperativo: 1) organizar as ações de controle da qualidade já exercida por diversos órgãos; 2) manter atualizado o cadastro da rede de abastecimento das concessionárias de abastecimento público de água, bem como os relatórios de inspeção e os planos de recuperação e investimento; 3) construir indicadores de qualidade da água que permitam tornar objetivo seu estado bio- 
físico-químico integrado às condições ambientais ao longo do tempo, e estabelecer ligações com as causas da poluição de um corpo d'água e possíveis políticas de restabelecimento da qualidade ambiental das águas de uma bacia hidrográfica; 4) criar bancos de dados georeferenciados com tratamento estatístico das informações por corpos d'água e bacias hidrográficas; e, sobretudo, 5) democratizar o acesso às informações sobre a qualidade natural e alteração da água, para todo e qualquer cidadão fluminense, através de formas eficientes de comunicação que facilite a compreensão das mesmas por não-especialistas em qualidade das águas. A informação é um grande instrumento de defesa dos cidadãos, pois quem está a par de seus direitos está sempre mais protegido.

Não obstante, e tendo em vista a atual setorialização e desarticulação entre os órgãos públicos envolvidos com o monitoramento e controle da qualidade das águas, bem como do prolongado estado de sucateamento em que eles se encontram, torna-se necessária, para a realização das tarefas enunciadas anteriormente, a criação de um Programa de Monitoramento e Controle da Qualidade das Águas Superficiais e Subterrâneas do Território Fluminense. Esse programa deveria ser estruturado com base nos princípios de descentralização, compartilhamento, participação e integração na gestão do meio ambiente. Tal programa, que estaria vinculado ao Conselho Estadual de Recursos Hídricos, deveria ser formado e administrado por especialistas dos poderes públicos federal, estadual e municipal, da comunidade científica, representantes de instituições de ensino, pesquisa e extensão, do setor produtivo (patrões e empregados), de movimentos sociais, de entidades ambientalistas e religiosas. Seu financiamento seria oriundo dos recursos do Fundo Estadual de Recursos Hídricos, criado pela lei no 3239/99.

Mas, tendo em vista a indistinção entre público e privado que caracteriza a gestão da res pública brasileira, duas condições básicas precisariam ser atendidas para possibilitar o êxito desse programa. Trata-se de duas condições diretamente relacionadas à sua governabilidade. Primeiro, que os representantes do Estado incorporem em suas atividades funcionais os preceitos constitucionais que fundamentam a Política Nacional de Recursos Hídricos (art. 20, III; 21, XIX; 22, IV; 24, VI; 26, I, da CF de 1988) e respeitem, pelo menos, cinco dos 12 princípios constitucionais básicos da administração pública: legalidade, moralidade, impessoalidade ou finalidade, publicidade e eficiência (art. 37, caput, da CF de 1988). Como nos lembra o insofismável Hely Lopes Meirelles (2001, p. 82), 
na Administração Pública não há liberdade nem vontade pessoal. Enquanto na administração particular é lícito fazer tudo que a lei não proíbe, na Administração Pública só é permitido fazer o que a lei autoriza. A lei para o particular significa “pode fazer assim”; para o administrador público significa “deve fazer assim”.

Segundo, que todos os integrantes do Sistema de Gerenciamento de Recursos Hídricos tenham, de forma equilibrada, e de fato, os direitos resguardados e a clareza a respeito dos seus deveres. Sem isso, a gestão integrada das águas será mera figura de retórica, persistindo o atual quadro de degradação socioambiental do Estado, onde a relação entre água, doença e saúde só tende a se agravar, sobretudo para as populações faveladas ou que vivem na periferia dos centos urbanos.

Ao mesmo tempo, como a questão ambiental é certamente política, e sua disposição invoca a interferência de cada cidadão no debate e na tomada de decisões, é urgente que se implemente ou se faça implementar no Estado do Rio de Janeiro a educação ambiental, na forma e com o alcance que determina a Constituição Federal de 1988, a Política Nacional da Educação Ambiental (lei $n^{0}$ 9.795/99) e demais leis e atos normativos nacionais e internacionais, a fim de que os habitantes das bacias hidrográficas do Estado do Rio de Janeiro exerçam uma cidadania ativa no controle da qualidade da água. Enquanto esse direito social fundamental não é regulamentado pelo poder público, todo e qualquer cidadão fluminense pode utilizar $O$ Código do Consumidor (lei Federal no 8.078/90) como subsídio para fazer inserir a educação ambiental no curriculum escolar ou na rede de ensino e exigir junto ao Ministério Público que as normas de potabilidade da água consumida sejam respeitadas quando da constatação de alteração do sabor e/ou do odor da mesma, alteração com implicações diretas sobre a saúde individual e coletiva.

\section{As novas idéias e as preocupacõos instáveis, variadas e ambíguas dos cidadãos em relação ao meio ambiente}

Antes de concluir as descrições e análises desenvolvidas anteriormente, devo frisar que as novas idéias são importantes para as mudanças sociais ou políticas, e a política de recursos hídricos suscita, certamente, novas idéias ou, pelo menos, uma reinterpretação de antigas idéias ou de idéias velhas de algumas décadas. Mas é importante nunca esquecer que as preocupações dos cidadãos com o meio ambiente sempre foram instáveis, variadas e ambíguas, e 
alcançaram raramente a intensidade necessária para forçar uma mudança radical das políticas, exceto quando os cidadãos agem de forma organizada e melhor qualificada para o exercício da cidadania. Além disso, a preocupação expressa pelos cidadãos ultrapassam freqüentemente suas preocupações reais, como testemunham suas escolhas de consumo, de moradia ou de transporte. Pode-se esperar que a emergência de uma crise ambiental como a escassez quantitativa e qualitativa de água doce nas próximas décadas provoque reações muito pontuais e não uma reorientação fundamental do pensamento ou do comportamento.

O fato de que as novas idéias sobre gestão de recursos hídricos não tenham ainda transformado substantivamente a administração pública do Estado do Rio de Janeiro ou os comportamentos individuais não significa, no entanto, que elas sejam ineficazes. Seu efeito se medirá ao longo das próximas décadas e não em anos, dependendo das mudanças que venham a ocorrer na forma como governantes e parlamentares se tornaram "donos do poder" desde a época da Colônia, mantendo com os cidadãos relações pessoais de favor, clientela e tutela, caracterizando a indistinção atual entre o público e o privado que organiza o aparelho do Estado no Brasil (Carvalho, 2001; Chauí, 2001; Dagnino, 2002; DaMatta, 2001; Faoro, 1957).

Esperar que tais acontecimentos marquem, ocasionalmente, mudanças de comportamentos em grande escala é, talvez, ilusório, fazendo com que se ignore nossa responsabilidade coletiva em produzir mudanças mais realistas. Grandes mudanças sociais ocorrem freqüentemente, mas, à exceção das revoluções, estendem-se sobre décadas ou períodos mais longos. Além disso, essas mudanças não se originam unicamente das políticas públicas e não ocorrem necessariamente por causa delas. As políticas podem, certamente, desempenhar um papel, mas não podem sozinhas forçar uma mudança social. O que elas podem, na verdade, é ajudar na interação das forças em jogo. Numerosos e distintos tipos de mudanças podem agir entre si. Nesse sentido, mesmo as mudanças individuais, que parecem inexpressivas, podem mostrar-se bastante úteis, uma vez reagrupadas.

\section{Considerações finais}

A mudança na forma de encarar os efeitos das atividades humanas sobre o meio natural expressa no marco legal brasileiro que disciplina a administração 
do meio ambiente é o produto do fim da crença na capacidade infinita do meio ambiente em suportá-los. Essa mudança passa a creditar às políticas públicas a expectativa de reversão do atual quadro de degradação dos recursos naturais. O grande mérito, portanto, do modelo de gestão de recursos hídricos brasileiro, modelo praticado, como vimos, de forma singular no Estado do Rio de Janeiro, refere-se, indubitavelmente, ao reconhecimento de que a água é um bem finito e limitado, de que há uma multiplicidade de usos convivendo num mesmo espaço territorial, a bacia hidrográfica, e que a água, dada a sua importância, é dotada de valor econômico e, portanto, passível de cobrança.

Contudo, temos um Estado que apregoa como suas as funções de gerência do bem público, de fazedor e mantenedor das leis e, principalmente, de equanimidade no desempenho dos seus papéis que, na prática, revela sua inépcia para cumprir essas funções e, mesmo, sua predileção por exercê-las, dependendo da situação social e/ou relacional das pessoas ou grupos envolvidos. Acredito que essa situação decorra das peculiaridades da nossa constituição histórica e jurídica descrita por inúmeros autores, sobretudo a da importação de leis e modelos de governo que não refletiam e nem refletem a experiência e a prática da ampla parcela dos atores da dinâmica territorial.

Ao mesmo tempo em que o poder público coloca à disposição das instituições gestoras uma multiplicidade de instrumentos técnicos, regulatórios, econômicos, de planejamento, etc., todos muito eficazes na sua concepção teórica, não há, em contrapartida, a completa compreensão por parte dos atores da dinâmica territorial sobre a sua efetividade, sua viabilidade prática e, por conseguinte, sua operacionalização no âmbito do planejamento e da gestão das bacias hidrográficas, dado que esse processo é bastante recente no Brasil. Outras dificuldades parecem se constituir em obstáculo à plena implementação dos instrumentos de gestão no Estado do Rio de Janeiro em base sustentável. À exceção do Município do Rio de Janeiro, constata-se: 1) a inexistência de divisões, departamentos, coordenações, secretarias ou comissões em boa parte dos municípios que incorporem a importância estratégica do gerenciamento dos recursos hídricos e do espaço costeiro, cujas estruturas são normalmente voláteis e dependentes dos interesses políticos vigentes, vinculados, portanto, às transitoriedades de governo; 2) a institucionalização de políticas públicas pelo poder executivo estadual dirigidas à gestão do uso e ocupação do solo e aos recursos hídricos sem uma democratização da informação adequada junto às administrações municipais; 3) deficiências na consolidação das articulações institucionais e da integração multissetorial. Em resumo, grande parte dos pro- 
blemas existentes atualmente em relação ao conjunto dos instrumentos de gestão se relaciona a questões institucionais, como a falta de articulação ou de pactuação político-institucional para a melhor operacionalização dos instrumentos de gestão; além do fato de haver uma distância crítica entre aqueles que constroem o arcabouço legal e aqueles que deveriam implementá-los localmente. Resultado: há um crescente aumento da degradação dos mananciais e de perda da qualidade das águas doces e salgadas urbanas no estado e na cidade do Rio de Janeiro.

\section{Referências}

ACSELRAD, Henri (Org.). Conflito social e meio ambiente no Estado do Rio de Janeiro. Rio de Janeiro: Relume Dumará: Fase, 2004.

CARDOSO, Maria Lúcia de Macedo. A democracia das águas na sua prática: o caso dos comitês de bacias hidrográficas de Minas Gerais.Tese (Doutorado em Antropologia Social)-PPGAS/Museu Nacional/Universidade Federal do Rio de Janeiro, Rio de Janeiro, 2003.

CARVALHO, José Murilo de. Cidadania no Brasil: o longo caminho. Rio de Janeiro: Civilização Brasileira, 2001.

CHAUÍ, Marilena de Souza. Brasil: mito fundador e sociedade autoritária. São Paulo: Editora Fundação Perseu Abramo, 2001.

DAGNINO, E. (Org.). Sociedade civil e espaços públicos no Brasil. Rio de Janeiro: Paz e Terra, 2002.

DAMATTA Roberto. Carnavais, malandros e heróis. 3. ed. Petrópolis: Vozes, 2001.

DO PARAÍBA às torneiras do Rio. O Globo, Rio de Janeiro, p. 26, 18 abr. 2004.

FAORO, Raimundo. Os donos do poder. Porto Alegre: Globo, 1957.

FUKS, Mario. Conflitos ambientais no Rio de Janeiro: ação e debate nas arenas públicas. Rio de Janeiro: Editora UFRJ, 2001.

IBGE. Pesquisa de informações básicas municipais 2001. Rio de Janeiro: FIBGE, 2003a.

IBGE. Atlas do censo demográfico 2000. Rio de Janeiro: FIBGE, 2003b. 
GALIMBERTI, Umberto. Psiche e tecne: o homem na idade de técnica. São Paulo: Paulus, 2004.

MACHADO, Carlos José Saldanha. A questão ambiental brasileira: uma análise sociológica do processo de formação do arcabouço jurídico-institucional, Revista de Estudos Ambientais, Blumenau, v. 2, n. 2-3, p. 5-20, jul./dez. 2000.

MACHADO, Carlos José Saldanha. A cobrança pelo uso da água: contribuição para a sua implementação no Estado do Rio de Janeiro. Revista Rio de Janeiro, Rio de Janeiro, n. 9, p. 55-75, jan./abr. 2003.

MACHADO, Carlos José Saldanha. Meandros do meio ambiente: v. 2: os recursos hídricos na economia e no cenário internacional. Rio de Janeiro: EPapers, 2004a.

MACHADO, Carlos José Saldanha (Org.). Gestão de águas doces. Rio de Janeiro: Interciência, 2004b.

MACHADO, Carlos José Saldanha; KLEIN, Helena Espellet. Água, doença, saúde e arcabouço institucional-legal: por uma gestão integrada das águas do Estado do Rio de Janeiro. Revista Rio de Janeiro, Rio de Janeiro, n. 11, p. 13-38, set./dez. 2003.

MEIRELLES, Hely Lopes. Direito administrativo brasileiro. 21. ed. São Paulo: Malheiros, 2001.

ÓRGÃOS ambientais viram sucata verde no Rio. O Globo, Rio de Janeiro, p. 40, 14 set. 2003.

TRIBUNAL DE CONTAS DO ESTADO DO RIO DE JANEIRO. Contas de gestão do governo: exercício 2002. Rio de Janeiro: TCE-RJ, 2003. 